\title{
Spasskyellina mandi n. sp. (Proteocephalidea: Monticelliidae), Parasite of Pimelodus ornatus Kner, 1857 (Pisces: Pimelodidae) of the Paraná River, Paraná, Brazil
}

\author{
Gilberto C Pavanelli+, Ricardo M Takemoto \\ Núcleo de Pesquisas em Limnologia, Ictiologia e Aqüicultura (NUPELIA), Universidade Estadual de Maringá, \\ Av. Colombo 5790, 87020-900 Maringá, PR, Brasil \\ Spasskyellina mandi $n$. sp. (Proteocephalidea: Monticelliidae) is described from the Siluriform fish \\ Pimelodus ornatus Kner, 1857, caught in the Paraná River, Paraná, Brazil. The new species differs from \\ other species of the same genus mainly by a fewer number of testes and by a larger osmoregulatory \\ canal. This is the second species of proteocephalidean cestode collected in $\mathrm{P}$. ornatus.
}

Key words: Proteocephalidea - Monticelliidae - Spasskyellina mandi n. sp. - Pimelodus ornatus Paraná River - Brazil

As a continuation to their study on parasites of fishes of the Paraná River, Porto Rico region, PR, Brazil, the authors describe a new species of proteocephalidean cestode, Spasskyellina mandi $\mathrm{n}$. sp. collected in Pimelodus ornatus Kner, 1857. According to Nomura (1984) the fish is a Siluriform fish found in the rivers Parnaíba, Negro and high Paraná, and in Mato Grosso, Goiás, Paraguay, Guianas, Bolivia, Peru and Venezuela. Recently Chambrier and Rego (1995) have made a description of Mariauxiella pimelodi which constitutes the first reference of a proteocephalid in the same species of fish.

\section{MATERIALS AND METHODS}

Twenty-eight specimens of $P$. ornatus were examined between March 1992 and February 1995. The fishes were caught in the Paraná River, near Porto Rico, PR. Immediately after capture, the fishes were identified and eviscerated, and the intestines were isolated and examined in Petri dishes containing a $0.65 \%$ physiological saline solution using a stereomicroscope. The isolated helminths were placed in distilled water to relax before the occurrence of death, in refrigerator or they were fixed in hot $10 \%$ formalin. Specimens for study in toto were stained with Delafield's haematoxylin or Langeron's alcoholic chloridric carmine, cleared in beechwood creosote and mounted in Canada

Supported by CNPq - PADCT/CIAMB

${ }^{+}$Corresponding author and research fellow CNPq. Fax: +55-44-226.1860. e-mail: nupelia@uem.br Received 28 February 1996

Accepted 16 August 1996 balsam. Pieces of strobila were embedded in paraffin wax, sectioned at $5 \mu \mathrm{m}$ and stained with haematoxylin eosin. The illustrations were prepared with a drawing tube and a NIKON YS 2 microscope. Measurements are in millimeters unless otherwise indicated, with ranges followed by mean within parentheses. The holotype and some paratypes were deposited in the Instituto Oswaldo Cruz Collection (CHIOC), Rio de Janeiro, RJ, Brazil. Prevalence, intensity of infection and mean intensity of infection are used according to Margolis et al. (1982).

\section{DESCRIPTION \\ PROTEOCEPHALIDEA MONTICELLIIDAE \\ Spasskyellina Freze, 1965 emend.}

Scolex globose. No metascolex. Suckers armed with several rows of minute spines. Ovary, testes and uterus entirely cortical. Uterine slit formed early. Uterine diverticula slightly or well developed. Longitudinal musculature slightly developed. Vagina always posterior to cirrus sac. In South American fishes.

\section{Spasskyellina mandi $\mathrm{n} . \mathrm{sp}$.} (Figs a-h)

Description - (Based on nine specimens, all measured). Medium size helminths. Acraspedote strobila, 2.09 - 60.39 (17.69) in length, bearing about 65 proglottides. Neck 0.42 - 0.75 (0.62) long. Mature proglottides slightly longer than wide $0.14 \mathrm{x}$ $0.19-0.80 \times 0.70(0.40 \times 0.38)$; gravid proglottides longer than wide $0.32 \times 0.26-1.79 \times 0.63(0.95$ $x$ 0.47). Small scolex, slightly differentiated from strobila $0.12 \times 0.13-0.22 \times 0.26(0.16 \times 0.21)$ with four antero-lateral suckers, $0.05-0.10(0.08)$ 

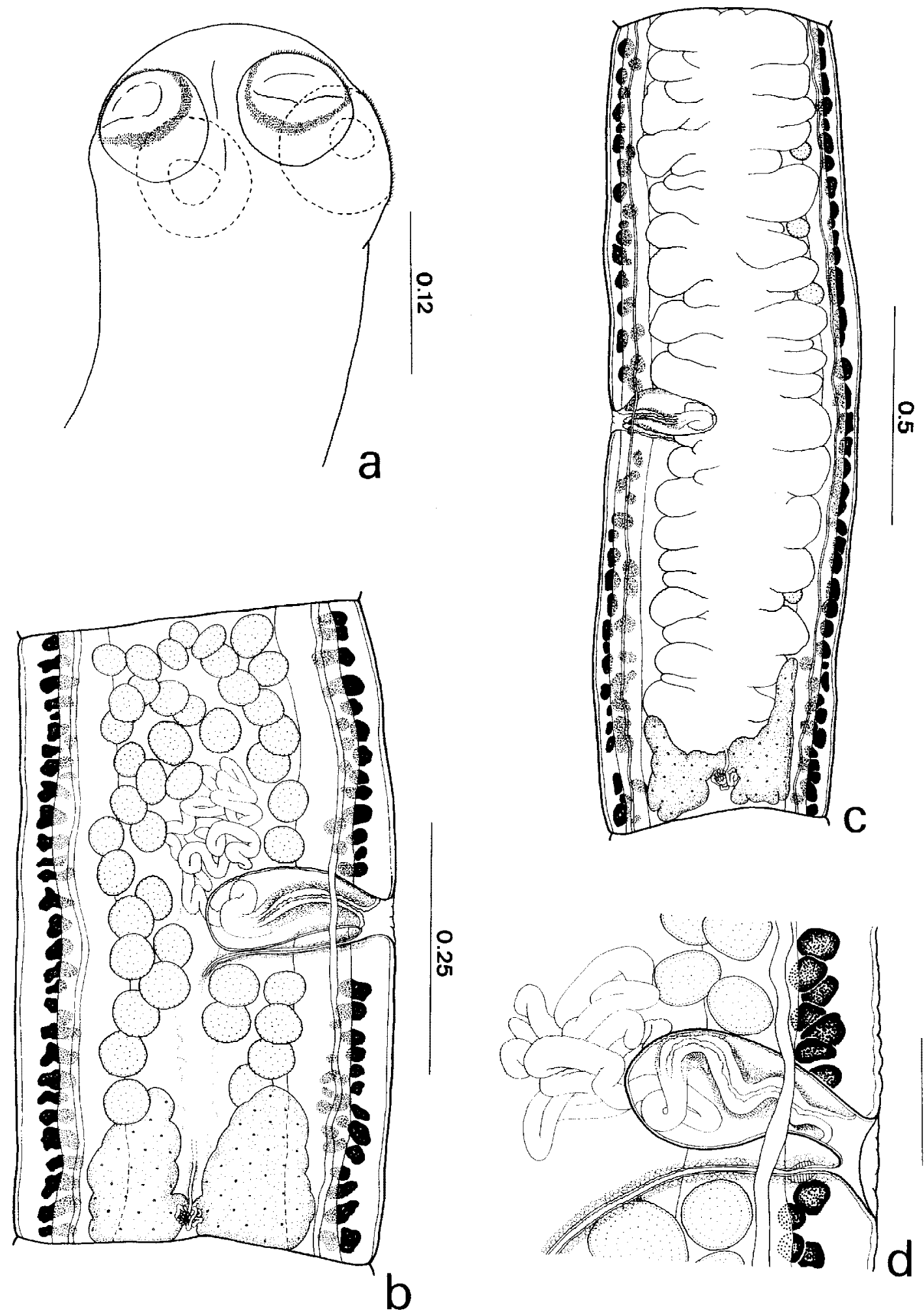

Spasskyellina mandi n. sp. a: scolex. b: mature proglottis, dorsal view. c: gravid proglottis, dorsal view. d: vagina and cirrus pouch. Scale in $\mathrm{mm}$. 

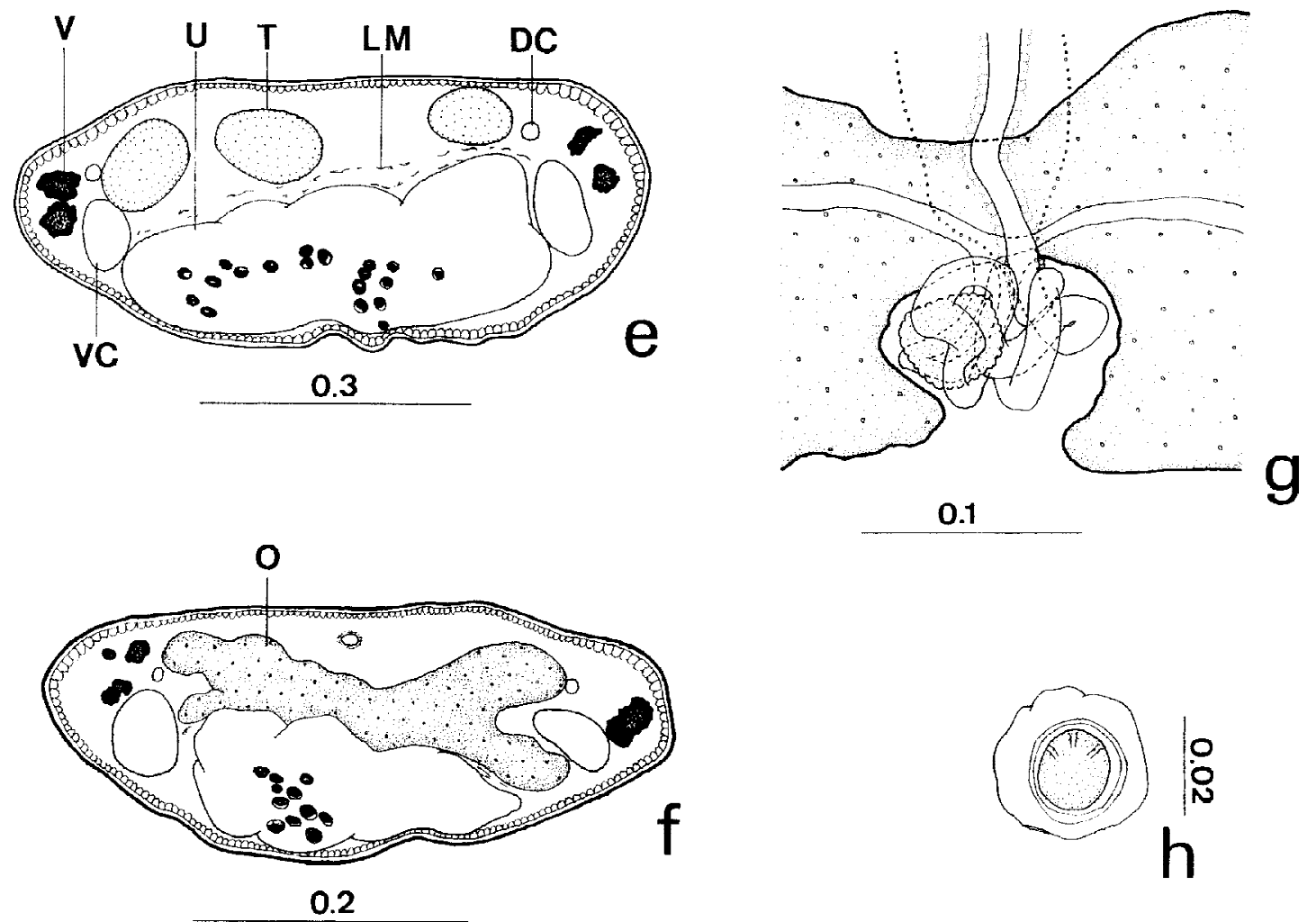

Spasskyellina mandi $\mathrm{n}$. sp. e, f: transverse section of proglottis. g: ootype complex, dorsal view. h: egg. Abbreviations: V = vitelline follicles; $\mathrm{U}=$ uterus; $\mathrm{T}=$ testes; $\mathrm{LM}=$ longitudinal musculature; $\mathrm{DC}=$ dorsal osmoregulatory canals; VC = ventral osmoregulatory canals; $\mathrm{O}=$ ovary. Scale in $\mathrm{mm}$.

in diameter, surrounded by small spines. Apical organ lacking. Metascolex absent. Internal longitudinal musculature inconspicuous. Ventral osmoregulatory canal broad, 0.025-0.082 (0.050) in diameter. Twenty-five to fifty-one (36) oval testes in only one cortical and dorsal field, extending to vitellaria with 6-13 (10) preporal, 5-9 (7) postporal and 14-30 (19) antiporal, with 0.02-0.05 (0.04) in diameter. Cirrus pouch claviform slender-walled, 0.13-0 .22 (0.18) long and 0.04-0.09 (0.06) wide, occupying $38-58 \%$ (48\%) of proglottis width in mature proglottides. Internal seminal vesicle coiled, ejaculatory duct a little longer than half length of cirrus pouch; cirrus short probably aspinose. Vas deferens highly coiled anterior to posterior end of cirrus sac, extending to the middle of proglottis. Genital pores irregularly alternated, situated chiefly on medial part of proglottis, but can be observed below the middle part of proglottis at 54-62\% (58\%) from anterior end of mature and gravid proglottides. Cortical and dorsal ovary with two lobes, 0.04-0.13 (0.08) long and 0.08-0.33 (0.20) wide, the lateral ovarian lobes overlap the osmoregulatory ducts laterally. Vagina not ciliated internally, always posterior to cirrus, with poorly developed sphincter. Vaginal duct dorsal to uterus, seminal receptacle present. Mehlis' gland 0.02-0.06 (0.04) in diameter. Compact cortical vitellaria, arranged in two lateral rows, extending to the whole proglottis length. Pre-formed cortical uterus early occupying only the porterior part of proglottis, with 18-28 (22) lateral branches per side. Eggs with external delicate membrane, 0.0275 in diameter, embryophore 0.0200 in diameter, oncosphere 0.015 in diameter. Final proglottids lacking eggs.

Taxonomic and ecological summary

Host: Pimelodus ornatus Kner, 1857

Locality: Porto Rico, Paraná River, State of Paraná, Brazil.

Site of infection: intestine

Prevalence: $75 \%$ (28 fishes examined, 21 parasited) Mean intensity of infection: 9

Specimens deposited: Instituto Oswaldo Cruz Collection (CHIOC) Nos 33679a (holotype) and 33679 b-d (paratypes)

Etymology: the name of the species is a reference to the popular name of the host. 
Remarks: the genus Spasskyellina established by Freze (1965) is chiefly characterized by suckers with spines, pre-formed uterus with slightly developed lateral diverticula and reproductory organs and vitelline in the cortical region. According to Rego and Pavanelli (1992) there are two species of the genus Spasskyellina: S. lenha (Woodland, 1933) and S. spinulifera (Woodland, 1935). Brooks (1995) presented the phylogenetic hypothesis for the Monticelliidae. In that hypothesis, S. lenha and $S$. spinulifera were considered sister species based on the presence of spinose suckers. Furthermore S. spinulifera was differentiated from S. lenha by having an average of 60 rather than 200 testes per proglottis, an apomorphic reduction in testes number within the Monticelliinae. Taking our study as a basis, we suggest the following improvements to that hypothesis. First, we agree that $S$. lenha and $S$. spinulifera are sister species; however, we recognize Spasskyellina as a distinct genus, and not part of Monticellia as proposed by Brooks (1995), on the basis of two synapomorphies: (1) spinose suckers and (2) the vagina being always posterior to the cirrus sac rather than alternating irregularly anteriorly and posteriorly. This leaves Monticellia as a genus without a synapomorphy and containing only two species: $M$. coryphicephala and $M$. megacephala. Second, we consider S. lenha to be the sister species of $S$. spinulifera plus $S$. mandi n. sp., which are linked by an apomorphic reduction in number of testes. S. lenha exhibits secondary folds on the tegument of the strobila, an apparent autapomorphy for that species. Furthermore, $S$. spinulifera has vitellaria in the ventral rather than lateral cortex, an autapomorphy for that species, and $S$. mandi $\mathrm{n}$. sp. has an average of 36 rather than 60 testes per proglottis, and unusually large ventral osmoregulatory ducts, both of these traits being apparent autapomorphies for the new species. S. mandi $\mathrm{n}$. sp. is also characterized by excretory canals with a large diameter, approximately $0.05 \mathrm{~mm}$, which is not found in the other species of the same genus. Besides, the genital pores open in the middle or slightly after the middle half of the proglottids, a characteristic which is not found in the two other species.

Freze (1965) and Rego (1994) stated that a characteristic of Spasskyellina is a uterus with slightly developed lateral diverticula. However the new species presented a uterus with a well developed lateral diverticula; moreover the three species of Spasskyellina has the vagina always posterior to cirrus sac. Thus it becomes necessary to emend the generic diagnosis of Spasskyellina given by Freze (1965) to include these feature.

\section{ACKNOWLEDGMENTS}

To Dr Amilcar A Rego, Instituto Oswaldo Cruz, Rio de Janeiro, RJ, Brazil for the critical revision of the manuscript.

\section{REFERENCES}

Brooks DR 1995. Phylogenetic hypothesis, cladistic diagnoses, and classification of the Monticelliidae (Eucestoda: Proteocephaliformes). Rev Brasil Biol 55: 359-367.

Chambrier A de, Rego AA 1995. Mariauxiella pimelodi n. g., n. sp. (Cestoda: Monticelliidae): a parasite of pimelodid siluroid fishes from South America. Syst Parasitol 30: 57-65.

Freze VI 1965. Essentials of cestodology. Vol. V. Proteocephalata in fish, amphibians and reptiles. Isdatel'stvo "Nauka” Moskva. (In Russian: English translation, Israel Program for Scientific Translation, Jerusalém, 1969) $597 \mathrm{pp}$.

Margolis L, Esch GW, Holmes JC, Kuris AM, Schad GA 1982. The use of ecological terms in parasitology (report of an ad hoc Committee of the American Society of Parasitologists). J Parasitol 68: 131-133.

Nomura H 1984. Dicionário dos Peixes do Brasil. Editerra Editorial, Brasília, 482 pp.

Rego AA 1994. Order Proteocephalidea Mola, 1928, p. 257-293. In LF Khalil, A Jones \& RA Bray (eds). Keys to the Cestode Parasites of Vertebrates, CAB International, Oxon, UK.

Rego AA, Pavanelli GC 1992. Checklist of the cestode order Proteocephalidea parasites from South America freshwater fishes. Rev UNIMAR, 14 (Supl.): 109-137. 